\title{
Radioactivity Measurement Method for Environmental Monitoring Gross Alpha/beta Activities in Drinking Water in Turkey
}

\author{
Gülten Kahraman,* Nazife Aslan, Mihriban Şahin and Simay Yüksek \\ Turkish Atomic Energy Authority, Sarayköy Nuclear Research and Training Center, Radiation Metrology Division, \\ Saray M., Atom C., No: 27 06983, Saray, Kazan, Ankara-TURKEY \\ *Corresponding author: E-mail: gulten.kahraman@taek.gov.tr; gltnhero@gmail.com \\ Phone No: +903128101553, Fax: +903128154307
}

Received: 18-09-2014

\begin{abstract}
The determination of gross alpha/beta activity concentrations of drinking water is the first step of the environmental monitoring studies and can provide a rapid evaluation of the radioactive content of a sample. In this study, a procedure using liquid scintillation spectrometry (LSS) for the simultaneously monitoring of gross alpha/beta activity concentration in drinking water was determined, verificated with proficiency test sample and applied to the real drinking water samples in Turkey. The results indicate that the method provides good accuracy and precision. LSS can be employed as a screening technique in high activity concentrations.
\end{abstract}

Keywords: gross alpha/beta activities; drinking water; liquid scintillation spectrometry (LSS); radioactivity measurement; environmental monitoring

\section{Introduction}

Water is one of the most important life sources of the people. In order to decide the use of water for the human consumption, physical, chemical, bacteriological and radioactive properties must be well defined. Especially the radioactivity in drinking water is not a new fact, having been present to some extent for thousands of years. Therefore, homeowners should be aware of the steps they might wish to take to test their private drinking water wells for radioactivity and to reduce their exposure.

Gross alpha/beta analysis is the first step in determining the level of radioactivity in drinking water. This test serves as a preliminary screening device and determines whether radionuclide specific analysis is required to further characterize the water. According to World Health Organization, ${ }^{1}$ water is considered adequate for human consumption when the screening level for gross alpha activity concentration is below $0.5 \mathrm{~Bq} \mathrm{~L}^{-1}$ and that for the gross beta activity concentration is below $1.0 \mathrm{~Bq} \mathrm{~L}^{-1}$. By EU Council Directive 2013/51/Euroatom of 22 October $2013^{2}$, recommended screening levels for gross alpha acti- vity and gross beta activity are $0,1 \mathrm{~Bq} \mathrm{~L}^{-1}$ and $1,0 \mathrm{~Bq} \mathrm{~L}^{-1}$, respectively in each member state.

This WHO guideline is adopted to National Legislation of Ministry of Health in Turkey. When the values (Gross $\alpha>0.5 \mathrm{~Bq} \mathrm{~L}^{-1}$ and Gross $\beta>1 \mathrm{~Bq} \mathrm{~L}^{-1}$ ) are higher, further analysis should be carried out in Turkey. ${ }^{3}$ The routine method used in our laboratory for monitoring gross alpha/beta activities is the "EPA 900.0 Gross Alfa and Gross Beta Radioactivity in Drinking Water" standard method. The method relies on gas-flow proportional counting (GFPC). The efficiency of the method is dependent on the water residue mass. The technique requires a uniformly thickness, homogeneous layer of residue material on the planchet. Multiple calibration standards are also needed to cover a range of residue masses. ${ }^{4}$ The method isn't suitable for the determination of radon or low-energy beta emitters such as tritium in drinking water. In the literature, there are various studies about procedures using liquid scintillation counting for the monitoring of gross alpha/beta activities in environmental water. ${ }^{5-7}$ Also, several studies have suggested using the liquid scintillation spectrometric (LSS) method instead of GFPC due to its advantages of higher detection efficiency and fa- 
ster analyzing time.$^{8-11}$ Liquid scintillation spectrometric is an analytical technique which measures activity of radionuclides from the rate of light photons emitted by a liquid sample. ${ }^{12}$ The LSS measurement technique is applicable to all forms of nuclear decay (alpha and beta particle, electron capture, and gamma-ray emitting radionuclides). LSS applications range from radioactivity analyses $\left({ }^{3} \mathrm{H},{ }^{222} \mathrm{Rn}\right.$ etc. $)$ in drinking water, food control for ${ }^{90} \mathrm{Sr}$, radioactive effluent measurements at nuclear power plants, emergency preparedness for nuclear power and homeland security, radiocarbon dating, biofuel and other bio-based material analyses. The LSS method also has been widely employed in radionuclide metrology. The aim of this study was to determine the procedure based on liquid scintillation spectrometry for measuring gross alpha/beta activities for environmental monitoring of the drinking water samples in Turkey. The established procedure with verification and comparison was applied to the real drinking water samples from various regions in Turkey. Firstly, the effect of the total dissolved salt concentration, $\mathrm{pH}$, type of vial (teflon coated polyethylene and low potassium glass vial) and volume and the type of scintillation cocktail were also studied to determine the best conditions for measuring gross alpha/beta activity in the drinking waters. For the method verification, spiked water samples at different concentrations were prepared from "Alpha High (AH-B11144) and Beta 2 (B2)" proficiency test exercise samples of the NPL-2011 proficiency test. Before spiking by AH-B11144 and B2 solutions, the water sample was chosen from a group of samples for which the gross alpha/beta proportional counter analysis results were lower than limit values. This was done to have samples that are representative of actual waters commonly encountered in the laboratory. Then for the application of the method to the actual comparison sample, IAEA proficiency test sample was used. More than 10 samples of drinking water from various regions in Turkey were prepared and measured in LSS according to the establish procedure.

\section{Experimental}

\section{1. Reagents and Solutions}

Deionized water was used in order to determine optimum measurement conditions and the minimum detectable activities (MDA). Two spike waters were prepared from TAI drinking water. TAI drinking water was obtained from a well in Turkish Aerospace Industries, Inc. area. It has the lowest activity and the minimum residue property at highest volume. NPL 2011 B2 and NPL 2011 (AH) proficiency test solutions containing beta and alpha emitting radionuclides, respectively were used. The gross beta activity of NPL $2011 \mathrm{~B} 2$ was assigned as $5.83 \pm 0.06$ $\mathrm{Bq} \mathrm{g}^{-1}(\mathrm{k}=2)$ by using LSS method. The gross alpha activity of NPL $2011(\mathrm{AH})$ was assigned as $44 \pm 12 \mathrm{~Bq} \mathrm{~g}^{-1}(\mathrm{k}$ $=2$ ) by means of LSS in the final proficiency test report. ${ }^{13}$
Ultima Gold LLT (UG LLT), Optiphase Hisafe 3 (OP HS 3) and Ultima Gold AB (UG AB) cocktails from Perkin Elmer were used as the scintillation cocktails. ${ }^{241} \mathrm{Am}$ and ${ }^{90} \mathrm{Sr} /{ }^{90} \mathrm{Y}$ standard solutions were used in the determination of the optimum PSA value. The activity of ${ }^{241} \mathrm{Am}$ standard solution (Isotope products, source no: $1263-71-3)$ is $7.48 \mathrm{kBq} \mathrm{g}^{-1}$ and reference date is on December 1 , 2007. The activity of ${ }^{90} \mathrm{Sr} /{ }^{90} \mathrm{Y}$ (Isotope products, source no: 1217-1-1) standard solution is $3.71 \mathrm{kBq}$ $\mathrm{g}^{-1}$ and reference date is on October 1, 2006. To prepare a quench set, ${ }^{3} \mathrm{H}$ standard solution containing $7.39 \mathrm{kBq} \mathrm{g}^{-1}$ was used from Isotope products (reference date is on $\mathrm{Au}$ gust 1, 2009 and source no: 1389-13-2). Different beta emitting standard radionuclide solutions: ${ }^{210} \mathrm{~Pb},{ }^{14} \mathrm{C},{ }^{134} \mathrm{Cs}$ and ${ }^{90} \mathrm{Sr} /{ }^{90} \mathrm{Y}$ obtained from Isotope products, ${ }^{40} \mathrm{~K}$ salt from IAEA RGK-1 and ${ }^{36} \mathrm{Cl}$ from NIST (SRM 4943) were used for the determination of the beta counting efficiency. All solvents and reagents $\left(\mathrm{CaCl}_{2}, \mathrm{NH}_{3}, \mathrm{HNO}_{3}\right.$ etc. $)$ were of analytical grade and used without purification.

\section{2. Instrumentation}

Activity measurements were performed using Wallac Quantulus 1220 low background liquid scintillation counter. The instrument is equipped with a pulse shape discrimination device (PSA) and an external standard of ${ }^{152} \mathrm{Eu}$ which allows to measure external spectral quench parameter [SQP(E)]. By using PSA, alpha and beta events were recorded in separate alpha and beta multi-channel analyzers. PSA level represents a dividing line to distinguish alpha events from beta ones. The optimum PSA levels were determined by calibrating with a set of pure ${ }^{241} \mathrm{Am}$ and ${ }^{90} \mathrm{Sr} /{ }^{90} \mathrm{Y}$ standard solutions. The misclassification of signals (spillover,\%) was defined as the percentage of the excess alpha counts when calibrating with a pure beta emitting standard or the percentage of the excess beta counts when calibrating with a pure alpha standard.

Quenching, the main interference for LSS, may affect the optimum PSA setting and counting efficiencies. Quench correction curves were obtained from using a set of quenched standards. The quench level was quantified with Spectral Quench Parameter of External standard, SQP(E).

Twenty-milliliter of teflon coated polyethylene and glass vials (Perken Elmer) were used.

Spectra were analyzed using EASY View Spectrum Analysis Software. The counting windows were set to channels 500-800 in the alpha spectrum and channels $50-900$ in the beta spectrum.

\section{3. Determination of the Optimum Measurement Conditions}

The optimum measurement conditions (cocktail type, cocktail: sample ratio, vial type, optimum $\mathrm{pH}$ value and total dissolved salt concentration effect) were deter- 
mined by using deionized water in order to measure gross alpha/beta activity concentration in drinking waters by using LSS method. According to ISO 11704 (Water quality-Measurement of gross alpha/beta activity concentration in non-saline water-Liquid scintillation counting method-2010 Edition), deionized water samples containing different $\mathrm{CaCl}_{2}$ concentrations (between 0 and 2000 $\mathrm{mg} \mathrm{L}^{-1}$ ) were prepared and heated to remove the dissolved ${ }^{222} \mathrm{Rn}$. The $\mathrm{pH}$ values of prepared deionized samples by using preconcentration procedure of this ISO method were adjusted to $1.7 \pm 0.2$ with $8 \mathrm{M} \mathrm{HNO}_{3}$ to avoid adsorption on container walls. The evaporated deionized water samples were prepared in different cocktail types (UG LLT, OP HS 3 and UG AB) at different cocktail: sample ratios $(12: 8,14: 6,16: 4)$ and some observations were done to determine the optimum cocktail: sample ratio at the optimum cocktail type. Later, vials were measured in LSS instrument and evaluated the values of count rate and SQP(E) for each sample. After that, the effect of vial type on sample quenching was investigated. For this purpose, samples on the glass and teflon coated polyethylene vials at the selected cocktail type and the optimum cocktail: sample ratio were prepared and counted in LSS. Finally, prepared samples at the different $\mathrm{pH}$ values (between 0.2 and 4.0) from the prepared evaporated deionized water at the selected cocktail: sample ratio were measured in the LSS instrument to investigate the $\mathrm{pH}$ effect on sample quenching.

\section{4. Determination of Optimum PSA Value}

The optimum PSA value was established by calculating alpha and beta misclassification at different PSA settings (50-150) with pure ${ }^{241} \mathrm{Am}$ and ${ }^{90} \mathrm{Sr} /{ }^{90} \mathrm{Y}$ standard solutions. The standard solutions were diluted to $6 \mathrm{~mL}$ evaporated deionized water $(\mathrm{pH}=1.7 \pm 0.2)$ in the measurement vials containing $14 \mathrm{~mL}$ of UG AB cocktail. The resulting mixture was shaken for 45 minutes, waited for 1 hour in the instrument for dark adaption and measured at 20 minutes counting time in LSS. The alpha misclassification as beta, $\mathrm{M}_{\alpha}$ and beta misclassification as alpha, $\mathrm{M}_{\beta}$ were calculated according to Equation (1) and (2), respectively and the graph of the alpha misclassification and beta misclassification versus PSA values was plotted. From this graph, the optimum PSA value was determined from the intersection point of the two lines.

$$
\begin{aligned}
\% M_{\alpha} & =\frac{N_{\alpha} \text { in } \beta M C A}{N_{\alpha} \text { in } \beta M C A+N_{\alpha} \text { in } \alpha M C A} * 100 \\
\% M_{\beta} & =\frac{N_{\beta} \text { in } \alpha M C A}{N_{\beta} \text { in } \beta M C A+N_{\beta} \text { in } \alpha M C A} * 100
\end{aligned}
$$

where $\mathbf{M}_{\alpha}=$ alpha misclassification as beta; $\mathrm{M}_{\beta}=$ beta misclassification as alpha; $\mathrm{N}_{\alpha}=$ measured count rate for al- pha; $\mathrm{N}_{\beta}=$ measured count rate for beta and MCA=multichannel analyzers.

\section{5. Preparation of Quench Set}

The quench set was prepared by " $14 \mathrm{~mL}$ UG AB plus $6 \mathrm{~mL}$ deionized water" cocktail, ${ }^{3} \mathrm{H}$ standard reference solution and quencher agent (nitromethane). The required amounts of ${ }^{3} \mathrm{H}$ standard reference and nitromethane were added to 10 vials containing the cocktail, respectively. Added amounts of nitromethane ranged from 20 to $120 \mu \mathrm{L}$. The quench sets were measured in the LSS instrument one more time in order to check the sample stability. The net count rate in cps was obtained using Easy View program and the activity of each sample mass was calculated from the sample mass and the tritium standard activity concentration [Eq. (3)]. After that, the value of efficiency for each sample was calculated by using the efficiency equation, Eq.(4) for each measurement. The quenched parameter, $\mathrm{SQP}(\mathrm{E})$ values were obtained from registry file. Then the Quench curve of tritium [Efficiency\% versus quench parameter, SQP(E)] was plotted and fitted to a polynomial equation [Eq. (5)].

$$
\begin{aligned}
& \text { Activity }^{\text {Acticity }} \text { std }_{\text {s }} * \text { Mass } \\
& \text { Efficiency }=\varepsilon=\frac{c p m}{d p m}=\frac{\text { count rate }}{\text { Activity }}
\end{aligned}
$$

Where efficiency $(\varepsilon)$ is defined as the ratio of the observed counts per minute $(\mathrm{cpm})$ to the disintegrations per minute (dpm).

$$
\begin{aligned}
& \varepsilon_{\mathrm{H}-3}=\mathrm{k}_{0}+\mathrm{k}_{1} * \mathrm{SQP}(\mathrm{E})+\mathrm{k}_{2} *[\mathrm{SQP}(\mathrm{E})]^{2}+ \\
& +\mathrm{k}_{3} *[\mathrm{SQP}(\mathrm{E})]^{3}+\ldots
\end{aligned}
$$

\section{6. Determination of Beta Counting Efficiency}

Mean beta counting efficiency was determined by using different beta emitting standard radionuclide solutions: ${ }^{210} \mathrm{~Pb},{ }^{14} \mathrm{C},{ }^{134} \mathrm{Cs},{ }^{40} \mathrm{~K},{ }^{90} \mathrm{Sr} /{ }^{90} \mathrm{Y}$ and ${ }^{36} \mathrm{Cl}$. The required amounts of these standard solutions were added to each vial containing $14 \mathrm{~mL}$ UG $\mathrm{AB}$ and $6 \mathrm{~mL}$ deionized water, respectively. Then, these vials were measured in LSS at $1 \mathrm{~h}$ counting time. Later, counting efficiency value for each radionuclide was calculated from the measured net counting rate, quench curve and CIEMAT/NIST efficiency tracing method. Thus, the mean beta counting efficiency was obtained from the average of these efficiencies.

The CIEMAT/NIST efficiency tracing method is a combination of theoretical calculations and the experimental data obtained from a counter by using a suitable tracer nuclide (e.g. ${ }^{3} \mathrm{H}$ ) to determine the counting efficiency of a radionuclide. This method is based on the free 
parameter and can be used for a variety of $\beta$-emitting or electron capture radionuclides. Free parameter is defined as the energy necessary to create a photoelectron at the photocathode of the photo multiplier tube (PMT). The free parameter establishes a link between the counting efficiency of the radionuclide under analysis and the tracer nuclide. The counting efficiency curve for the radionuclide under analysis is then obtained as a function of the counting efficiency of the tracer. The relationship between the tritium efficiency and the radionuclide efficiency under the same conditions is calculated using the CIEMAT/NIST program [CN2005 program (E. Gunther, PTB/Latest version august 2005)]. Input data for the program include atomic and nuclear data of the radionuclides of interest, the data on LS cocktail used the composition of the cocktail and the ionization quench parameter $(\mathrm{kB})$. Data for many radionuclides and the most common used liquid scintillation cocktails can be found in this program. The efficiency of radionuclide is calculated by using the following polynomial equation obtained from the CIEMAT/NIST program, respectively:

$$
\varepsilon_{\text {radionuclide }}=\mathrm{k}_{0}+\mathrm{k}_{1} * \varepsilon_{\mathrm{H}-3}+\mathrm{k}_{2} *\left(\varepsilon_{\mathrm{H}-3}\right)^{2}+\mathrm{k}_{3} *\left(\varepsilon_{\mathrm{H}-3}\right)^{3}+\ldots
$$

Firstly, the tritium efficiency values $\left(\varepsilon_{\mathrm{H}-3}\right)$ were calculated by using polynomial equation [Eq. (5)] obtained from the quench curve of $\mathrm{H}-3$ and $\mathrm{SQP}(\mathrm{E})$ values from the instrument output for radionuclide interested. Then, the efficiency of radionuclide interested versus efficiency of ${ }^{3} \mathrm{H}$ was calculated using the CIEMAT/NIST program for the given cocktail and $\mathrm{kB}$ value. Thus, the efficiency values for radionuclide interested could be calculated from this polynomial equation [Eq. (6)].

\section{7. Verification of the Method for Measuring of Gross alpha/beta Activity in Drinking Water}

The verification samples were composed of drinking waters containing different amounts of alpha and beta emitting radionuclides. TAI drinking water was used for this purpose. Two verification samples were prepared by using NPL 2011 B2 and NPL 2011 (AH) proficiency test solutions containing beta and alpha radionuclides, respectively. These are called as TAI-1 and TAI-2. Total volume of each sample was $2000 \mathrm{~mL}$. The compositions of TAI-1 and TAI-2 drinking water are given below.

1) the gross alpha and beta activities of the TAI-1 drinking water were $2.90 \mathrm{~Bq} \mathrm{~kg}^{-1}$ and $3.04 \mathrm{~Bq}$ $\mathrm{kg}^{-1}$, respectively.

2) the gross alpha and beta activities of the TAI-2 drinking water were $1.43 \mathrm{~Bq} \mathrm{~kg}^{-1}$ and $2.56 \mathrm{~Bq}$ $\mathrm{kg}^{-1}$, respectively.

The samples for gross alpha/beta analysis were prepared from $500 \mathrm{~mL}$ TAI water samples. The $\mathrm{pH}$ of sam- ples were adjusted to about $\mathrm{pH}=3-4$ with $\mathrm{NH}_{3}$ and then, they were evaporated to $\sim 20 \mathrm{~mL}$ under IR lamp at $80^{\circ} \mathrm{C}$. The $\mathrm{pH}$ value of the concentrated sample was controlled and adjusted to $\mathrm{pH}=1.7 \pm 0.2$. The samples for counting were taken $6 \mathrm{~mL}$ from the concentrated samples and were transferred to plastic vials containing $14 \mathrm{~mL} \mathrm{UG} \mathrm{AB}$. The samples were mixed homogenously and counted $240 \mathrm{mi}-$ nutes at optimum PSA value in the Wallac 1220 Quantulus LSS one more time. Blank was prepared by applying the same procedures for samples from $500 \mathrm{~mL}$ of deionized water.

The activity values in alpha and beta windows [from Eq.(7)] were calculated from the measured net counting rate in these windows, respectively.

$$
\operatorname{Activity}(B q / g)=\frac{\text { Net count rate }(\text { cps })}{\text { Efficiency* } \operatorname{Mass}(g)}
$$

Minimum detectable activity values (MDA) for alpha and beta radionuclides were calculated using Currie's expression ${ }^{14}$ from the measurement of blank sample.

\section{8. Application of the Method to the Actual Comparison Sample}

For this purpose, 2013 ALMERA proficiency test sample (IAEA-TEL-2013-04 Sample 2) was used. Sample was prepared from this actual comparison sample without preconcentration process because of its high activities (alpha and beta activities) and counted in LSS according to determined procedure.

\section{9. Determination of Gross Alpha/beta Activity in Real Drinking Water Sample}

The developed procedure was applied to real drinking water samples. More than 12 samples (5 $\mathrm{L}$ for each) from various regions in Turkey were used. The samples were treated with the sample preparation procedure and subsequently analyzed by LSS instrument.

\section{Results and Discussion}

The gross alpha/beta activity concentrations were determined in drinking water using LSS method with the PSA. Firstly, the effect of total dissolved salt concentrations, type and volume of scintillation cocktails, sample p$\mathrm{H}$ and vial type upon the gross alpha/beta values were investigated.

Accuracy of the method was verificated using spike water samples at optimized measurement conditions. The developed method was implemented by using actual comparison sample and applied to real drinking water samples collected from various regions in Turkey. 


\section{1. Optimum Measurement Conditions}

\section{1. 1. Effect of Type and Volume of Scintillation Cocktail and Total Dissolved Salt Concentration}

The effect of total dissolved salt concentration at three cocktail types (UG LLT, OP HS 3 and UG AB) and three cocktail: water ratios $(12: 8,14: 6,16: 4)$ were evaluated using the deionized water containing $0,250,500$, $1000,1500,2000 \mathrm{mg} \mathrm{L}^{-1}$ concentration of $\mathrm{CaCl}_{2}$.

The results are given in Figure 1. As a result of these experiments, the optimum cocktail: sample ratio was selected as (14:6); samples in this ratio were homogeneous and transparent. In addition, samples prepared using UG $\mathrm{AB}$ were less quenched than those prepared using other cocktails (Figure 2).

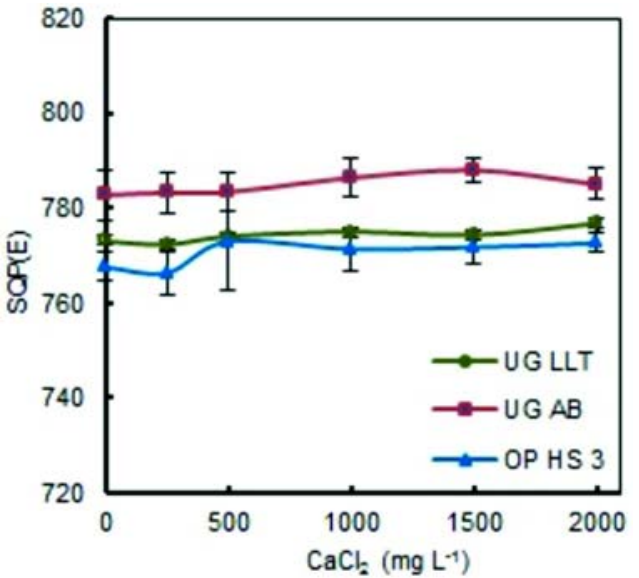

Figure 2. Relationship between SQP(E) value and total dissolved salt amount, $\mathrm{CaCl}_{2}$ at 14:6 scintillation deionized water ratio
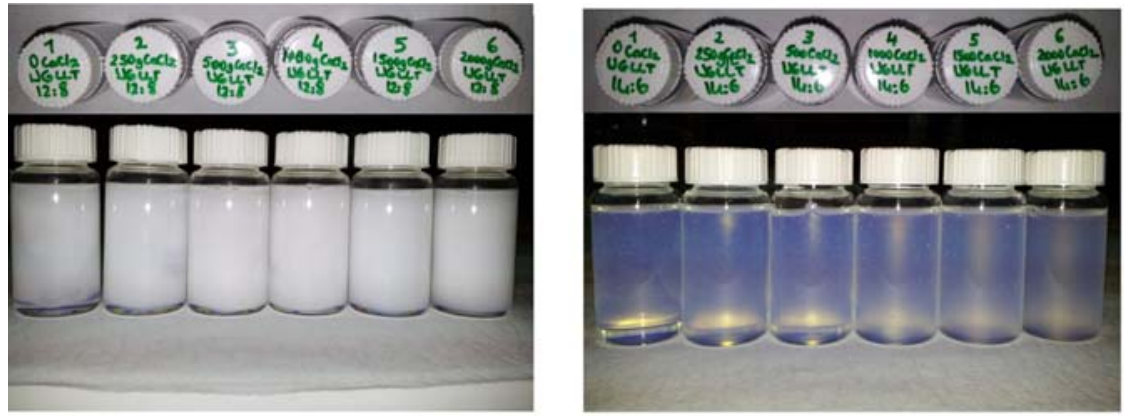

UG LLT
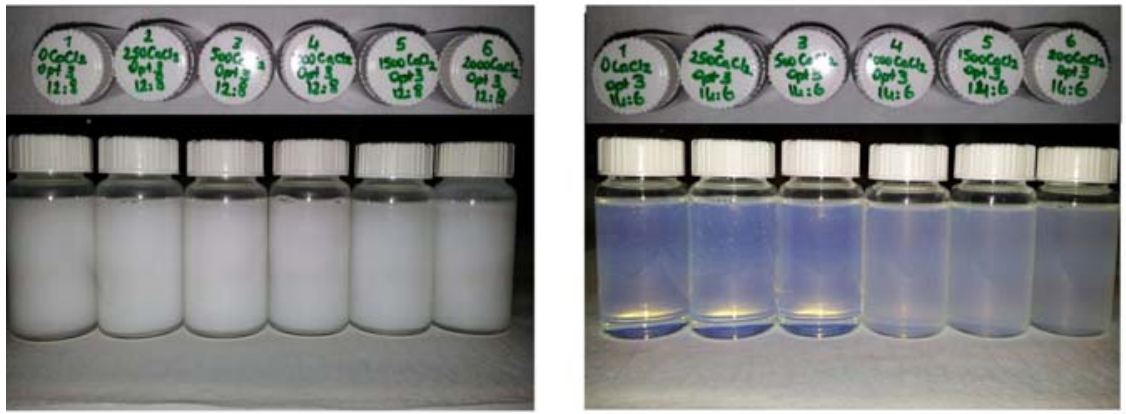

OP HS 3

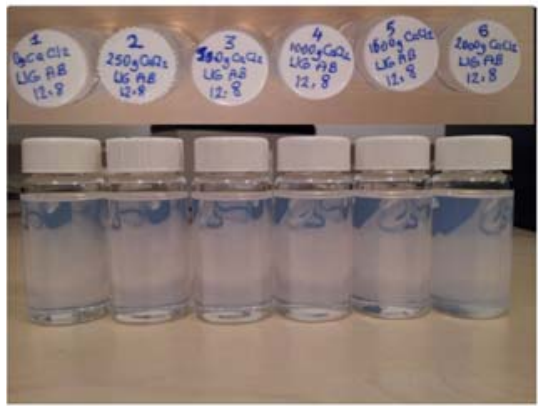

UG $A B$
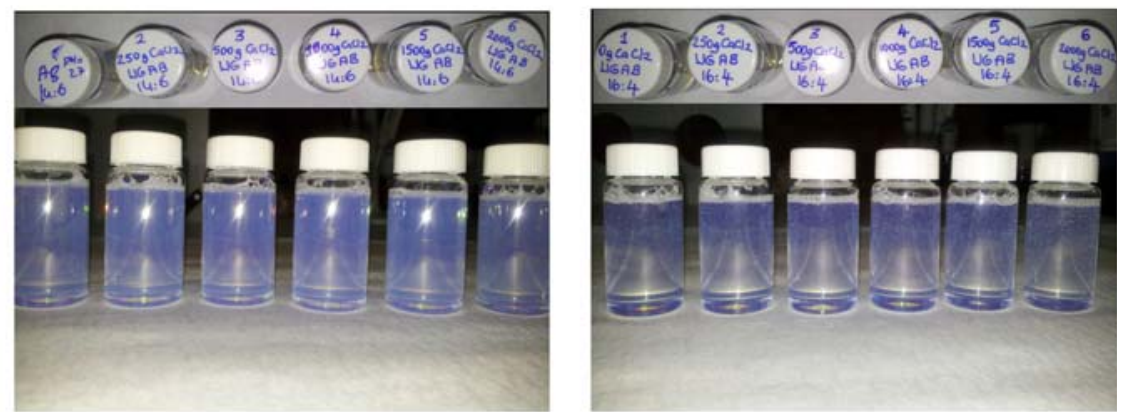

cocktail:sample ratio

$(14: 6)$

$(16: 4)$

Figure 1. The effect of total dissolved salt concentration at different cocktail types and different cocktail: deionized water ratios (Vials from 1 to 6 contains $0,250,500,1000,1500,2000 \mathrm{CaCl}_{2} \mathrm{mg} \mathrm{L}^{-1}$, respectively) 
The total dissolved salt effect on sample quenching was investigated by using prepared deionized water and three different cocktails at the selected cocktail: sample ratio. In these experiments, it was observed that there was no correlation between the total dissolved salt amounts and SQP(E) values and these correlations are seen in Figure 2 .

\section{1. 2. Effect of $\mathrm{pH}$}

The $\mathrm{pH}$ effect on quenching was investigated by using the evaporated deionized water in UG AB cocktail at the selected cocktail: sample ratio (14:6). It was observed that there was very little $\mathrm{SQP}(\mathrm{E})$ changing between $\mathrm{pH}$ 1.5 and 2.5 but $\mathrm{SQP}(\mathrm{E})$ decreased under $\mathrm{pH} 0.8$ value. There was no correlation between $\mathrm{pH}$ value and quench parameter, $\mathrm{SQP}(\mathrm{E})$ at our working $\mathrm{pH}$ value $(\mathrm{pH}=1.70 \pm$ 0.05) (Figure 3).

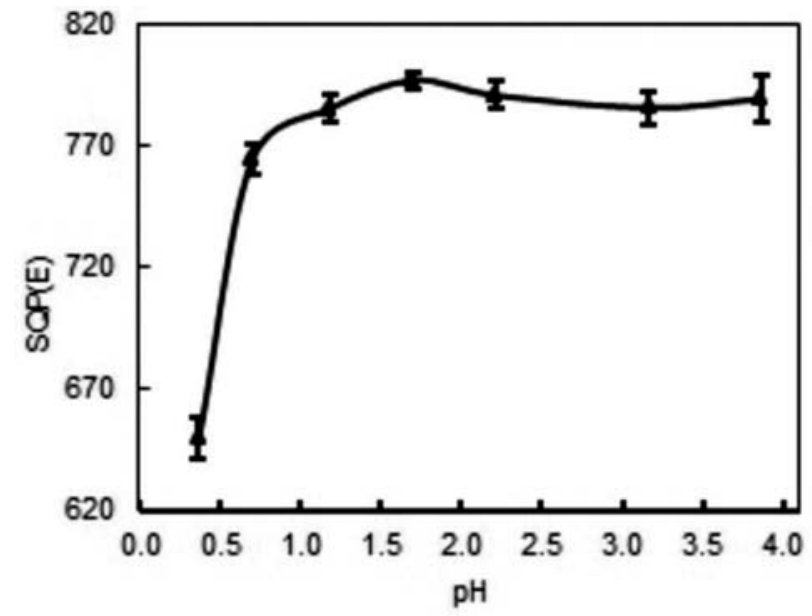

Figure 3. The $\mathrm{SQP}(\mathrm{E})$ variations as a function of $\mathrm{pH}$ for deionized water

\section{1. 3. Effect of Vials}

Commercial standard $20 \mathrm{~mL}$ of low-potassium borosilicate glass vial and teflon coated polyethylene vial were used to compare the vial effect on quenching and background count rate. From the data presented in Table 1 , it was indicated that the SQP(E) and background count rate values were significantly different for two types vials. Average background count rates were about $4.586 \pm 0.557$

Table 1. The vial effect on quenching, SQP(E) $6 \mathrm{~mL}$ deionized water $+14 \mathrm{~mL} \mathrm{UG} \mathrm{AB}, \mathrm{pH}=1.70 \pm 0.05$, counting time $=15 \mathrm{~min}]$

\begin{tabular}{lcc}
\hline $\begin{array}{l}\text { Vial } \\
\text { Type }\end{array}$ & $\begin{array}{c}\text { Mean } \\
\text { SQP(E) }\end{array}$ & $\begin{array}{c}\text { Mean count } \\
\text { rates, } \mathbf{c p m}\end{array}$ \\
\hline $\begin{array}{l}\text { Teflon coated } \\
\text { polyethylene vial }\end{array}$ & 796.59 & $4.586 \pm 0.557$ \\
$\begin{array}{l}\text { Low-potassium } \\
\text { glass vial }\end{array}$ & 781.96 & $22.830 \pm 1.246$ \\
\hline
\end{tabular}

cpm and $22.830 \pm 1.246 \mathrm{cpm}$ for teflon coated polyethylene vial and low-potassium glass vial, respectively. The background count rates obtained from low-potassium glass vial were obviously higher than that from the teflon coated polyethylene vial. It can be said that this observation may be related to the $\mathrm{K}-40$ contents of glass vials as we expect. $\mathrm{K}-40$ is responsible for the higher beta count rate in the low energy window.

As a result of these studies, we chosen the optimum measurement conditions as cocktail: sample ratio $=14: 6$, $\mathrm{UG} \mathrm{AB}$ cocktail and $\mathrm{pH}=1.70$ for the determination of gross alpha/beta activity in drinking waters (Table 2).

Table 2. Optimum measurement conditions

\begin{tabular}{ll}
\hline Parameters & Optimum value \\
\hline scintillation cocktail: & $14: 6$ \\
sample ratio (v/v) & \\
scintillation cocktail & Ultima gold $\mathrm{AB}$ \\
vial & teflon coated polyethylene \\
working $\mathrm{pH}$ & $1.70 \pm 0.05$ \\
preconcentration rate of water & $1 / 25$ \\
\hline
\end{tabular}

\section{2. Optimization of PSA Setting}

Measurement conditions were established by optimizing pulse-shape discrimination to achieve minimal interference. For this purpose, the percentages of misclassification obtained by calibrating with an ${ }^{241} \mathrm{Am}$ standard solution and a ${ }^{90} \mathrm{Sr} /{ }^{90} \mathrm{Y}$ (in secular equilibrium, activity of ${ }^{90} \mathrm{Sr}$ ) standard solution were plotted against the PSA levels as shown in Figure 4. As can be seen from the figure, the beta events were less misclassified than the alpha events along with the increasing PSA levels. On the other hand, the alpha events were found to have an increasing tendency in misclassification when the PSA levels increased. The crossover point of the two calibration curves was set as the best discrimination parameter and the optimum PSA value was determined as 87 which there is equal and

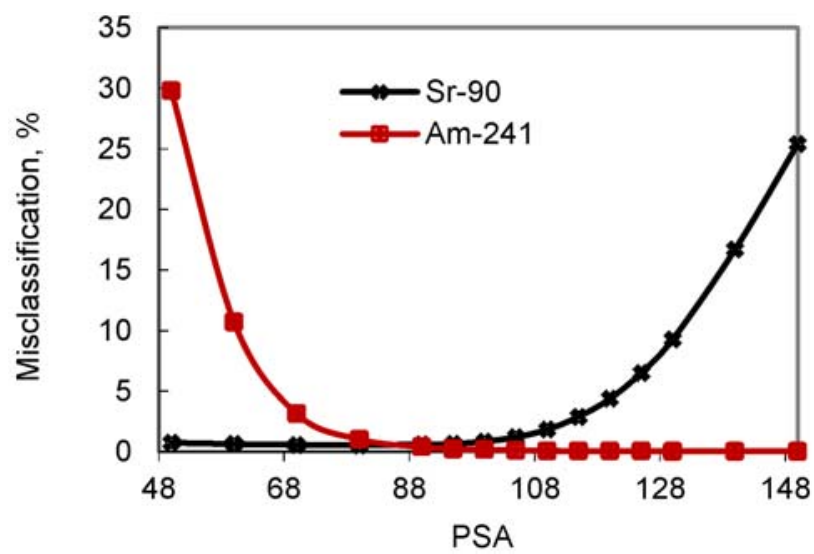

Figure 4. The graphic of the optimum PSA level determination for plastic vial in UG AB cocktail 
minimum spill of alpha pulses into the beta MCA and beta pulses into the alpha MCA.

\section{3. Method Verification}

\section{3. 1. Minimum Detectable Activity (MDA)}

The minimum detectable activity (MDA), Eq. (8) was calculated from the measurement of blank vial in the same conditions as samples using the formula reported by Currie. $^{14}$

$$
M D A=\frac{\left\lfloor\left(2.71+4.65 \sqrt{N_{b}}\right)\right\rfloor}{\varepsilon * V * t}
$$

Where $\mathrm{N}_{b}$ is background counts (cpm), $\varepsilon$ is the detection efficiency $\left(\mathrm{cpm} \mathrm{dpm}^{-1}\right), V$ is the sample volume and $t$ is the counting time in minute. The MDA values were calculated as $0.013 \mathrm{~Bq} \mathrm{~L}^{-1}$ for gross alpha and $0.075 \mathrm{~Bq} \mathrm{~L}^{-1}$ for gross beta. It was also shown that MDA for beta was higher, which was resulting from the relatively higher background. ${ }^{5}$

\section{3. 2. Determination of Gross alpha/beta Activity in Spike Drinking Water Sample}

The verification test of the procedure was performed using spiked TAI drinking water samples. The obtained experimental results for gross alpha/beta measurements compared to the reference values of activity in the added spike solutions are presented in Table 3.

In calculation, alpha and beta counting efficiencies were needed. Alpha counting efficiency is approximately $100 \%$ for almost all alpha decays using a liquid cocktail. ${ }^{15}$

Mean beta counting efficiency was determined as 95\% by using different beta emitting standard radionuclide solutions: ${ }^{210} \mathrm{~Pb},{ }^{14} \mathrm{C},{ }^{134} \mathrm{Cs},{ }^{40} \mathrm{~K},{ }^{90} \mathrm{Sr} /{ }^{90} \mathrm{Y}$ and ${ }^{36} \mathrm{Cl}$. As shown in Table 3, the percentage deviations of the measured values with respect to the added values were within the range from $3.79 \%$ to $4.19 \%$ for gross alpha while those were from $3.29 \%$ to $9.42 \%$ for gross beta. It is clear from the table that the experimental values were consistent with the reference values.

The results are also evaluated in terms of $\mathrm{z}$-test, $\xi$-test and relative uncertainty outlier tests. A result was only classified as 'in agreement' when these three tests were passed. A failure to pass one of these tests resulted in a classification 'questionable'. Failure of both the $\xi$ - test and $\mathrm{z}$-test resulted in a classification "discrepant". ${ }^{13}$ The validity of the method was satisfactory if the results for which the absolute values of the $\xi$-score and the $\mathrm{z}$-score were both less than or equal to 2.576 . Thus, the validity of proposed method was satisfactory according to the $\xi$-score and the $\mathrm{z}-$ scores.

Table 3. The experimental results for gross alpha/beta compared to reference values of activity concentration in added spike solution

\begin{tabular}{|c|c|c|c|c|c|c|c|c|c|c|c|c|}
\hline \multirow[t]{2}{*}{$\begin{array}{l}\text { Sample } \\
\text { code }\end{array}$} & \multicolumn{2}{|c|}{$\begin{array}{l}\text { Added activity, } \\
\left(\mathrm{A}_{\mathrm{ref}}\right), \mathrm{Bq}^{-1}\end{array}$} & \multicolumn{2}{|c|}{$\begin{array}{l}\text { Measured activity by LSS, } \\
\qquad\left(\mathrm{A}_{\mathrm{exp}}\right), \mathrm{Bq}^{-1}\end{array}$} & \multicolumn{2}{|c|}{$\begin{array}{l}\text { Relative } \\
\text { Bias }(\%)\end{array}$} & \multicolumn{2}{|c|}{$\xi^{a}$} & \multicolumn{2}{|c|}{ Z-score ${ }^{b}$} & \multicolumn{2}{|c|}{$\mathbf{R}_{\exp }^{c}$} \\
\hline & alpha & beta & alpha & beta & alpha & beta & alpha & beta & alpha & beta & alpha & beta \\
\hline$\overline{\text { TAI-1 }}$ & $2.90 \pm 1.60$ & $3.04 \pm 0.20$ & $3.01 \pm 1.66$ & $3.14 \pm 0.22$ & 3.79 & 3.29 & 0.05 & 0.34 & 0.65 & 0.56 & 0.55 & 0.07 \\
\hline TAI-2 & $1.43 \pm 1.56$ & $2.56 \pm 0.21$ & $1.49 \pm 1.64$ & $2.29 \pm 0.19$ & 4.19 & 9.42 & 0.03 & -0.95 & 0.72 & -1.81 & 1.10 & 0.08 \\
\hline
\end{tabular}

a) $\xi$ score $: \zeta=\frac{A_{\exp }-A_{r e f}}{\sqrt{U_{\text {exp }}^{2}+U_{r e f}^{2}}}$, Where; $\xi$ is $\xi$ score, $\mathrm{A}_{\exp }$ is the experimental value, $\mathrm{A}_{\text {ref }}$ is the assigned value, $\mathrm{U}_{\exp }$ is the standard uncertainty of the experimental value and $U_{\text {ref }}$ is the standard uncertainty of reference value

b) Z-Score: $Z=\frac{A_{\text {exp }}-A_{\text {ref }}}{\sigma_{p}}=\frac{A_{\text {exp }}-A_{\text {ref }}}{0,05823 A_{\text {nf }}}$ Where; $\mathrm{s}_{\mathrm{p}}$ is standard uncertainty for proficient assessment in $\mathrm{Bq} \mathrm{g} \mathrm{g}^{-1}$. The factor of 0.05823 used to calcula te the $\mathrm{z}$-score is the ratio between 0.15 and 2.576

${ }^{\text {c) }} R_{\text {exp }}=\frac{U_{\text {exp }}}{A_{\text {exp }}}$, where; $R_{\text {exp }}$ is relative uncertainty of the measured value ${ }^{13}$

Table 4. Uncertainty budget of gross alpha/beta activity concentrations in TAI-1 $(\mathrm{k}=1)$

\begin{tabular}{lcc}
\hline Uncertainty component & $\begin{array}{c}\text { Relative uncertainty (\%) } \\
\text { on the alpha activity concentration }\end{array}$ & $\begin{array}{c}\text { Relative uncertainty (\%) } \\
\text { on the beta activity concentration }\end{array}$ \\
\hline Counting statistic (including background) & 1.30 & 1.61 \\
Weight & 0.42 & 0.42 \\
Counting efficiency & - & 0.75 \\
Misclassification & 0.019 & 0.014 \\
SQP(E) & 0.02 & 0.02 \\
activity from NPL sample & 55.06 & 6.77 \\
\hline Combined uncertainty (quadratic sum) (\%) & $\mathbf{5 5 . 0 8}$ & $\mathbf{7 . 0 1}$ \\
\hline
\end{tabular}




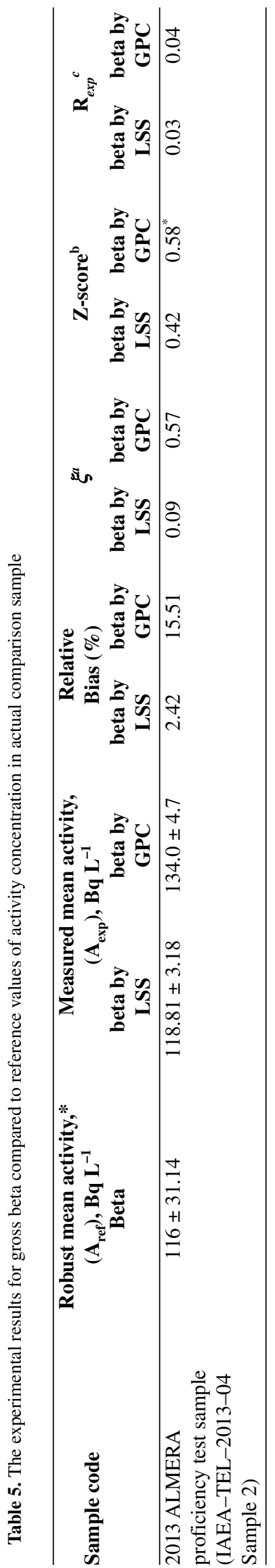

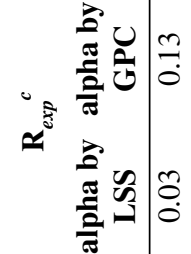

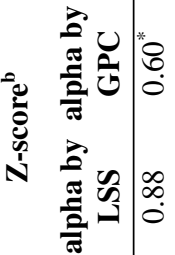

$\overrightarrow{0}$

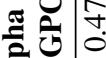

in

है

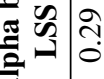

The uncertainty associated with the activity concentration has been calculated according to the appropriate rules of uncertainty propagation to give a combined standard uncertainty. The combined uncertainty is the estimated standard deviation equal to the positive square root of the total variance obtained by combining all variance and covariance components using the law of propagation of the uncertainty.

The parameters contributing to the uncertainty budget include the uncertainties in the counting statistics, detector efficiency, quench parameter [SQP(E)], misclassification, mass of sample and activities of the NPL proficiency test solutions. The total uncertainty due to all parameters is presented in Table 4.

Combined standard uncertainty of sample was calculated as a $7.01 \%$ for gross beta and $55.08 \%$ for gross alpha. The major contributions for beta emitting come from the counting statistics and the uncertainty of the NPL 2011 B2 proficiency test solution. But, the major contribution for alpha emitting comes from the uncertainty of the NPL 2011 (AH) proficiency test solution. The uncertainty due to misclassification and quench parameter are considered to be negligible compared to the other uncertainty components.

\section{3. 3. Application of the Method to the Actual Comparison Sample}

The comparison tests of the procedure were performed using 2013 ALMERA proficiency test sample (IAEA-TEL-2013-04 Sample 2). The obtained experimental results for gross alpha/beta measurements compared to the real values of activities are presented in Table 5 and 6 . The MDA values were calculated as $0.300 \mathrm{~Bq} \mathrm{~L}^{-1}$ for gross alpha and $1.881 \mathrm{~Bq} \mathrm{~L}^{-1}$ for gross beta.

\section{3. 4. Determination of Gross Alpha/beta Activity in Real Drinking Water Sample}

The results of gross alpha and beta measurements of 12 drinking water samples by LSS were reported in Table 7. The 
Table 6. The experimental results for gross alpha compared to reference values of activity concentration in actual comparison sample

\begin{tabular}{lcc}
\hline \multirow{2}{*}{ Sample code } & \multicolumn{2}{c}{ Measured mean activity by LSS, } \\
& Blpha & Beta \\
\hline S_01 & $<\mathrm{MDA}_{\alpha}$ & $<\mathrm{MDA}_{\beta}$ \\
S_02 & $0.139 \pm 0.007$ & $<\mathrm{MDA}_{\beta}$ \\
S_03 & $0.059 \pm 0.005$ & $0.235 \pm 0.015$ \\
S_04 & $0.044 \pm 0.003$ & $0.064 \pm 0.006$ \\
S_05 & $0.016 \pm 0.003$ & $0.072 \pm 0.009$ \\
S_06 & $0.039 \pm 0.003$ & $0.065 \pm 0.008$ \\
S_07 & $0.029 \pm 0.003$ & $<\mathrm{MDA}_{\beta}$ \\
S_08 & $<\mathrm{MDA}_{\alpha}$ & $<\mathrm{MDA}_{\beta}$ \\
S_09 & $0.215 \pm 0.008$ & $0.393 \pm 0.022$ \\
S_10 & $0.042 \pm 0.004$ & $0.076 \pm 0.011$ \\
S_11 & $<\mathrm{MDA}_{\alpha}$ & $0.087 \pm 0.006$ \\
S_12 & $0.023 \pm 0.004$ & $<\mathrm{MDA}_{\beta}$ \\
S_13 & $0.102 \pm 0.003$ & $0.144 \pm 0.007$ \\
\hline
\end{tabular}

$\mathrm{MDA}_{\alpha}=0.011 \mathrm{~Bq} \mathrm{~L}^{-1}$ and $\mathrm{MDA}_{\beta}=0.058 \mathrm{~Bq} \mathrm{~L}^{-1}$

gross alpha activity varies from $0.016 \pm 0.003 \mathrm{~Bq} \mathrm{~L}^{-1}$ to $0.215 \pm 0.008 \mathrm{~Bq} \mathrm{~L}^{-1}$, while the gross beta activities were detected from $0.064 \pm 0.006$ to $0.393 \pm 0.022 \mathrm{~Bq} \mathrm{~L}^{-1}$. These values are both below the stated intervention levels for National Legislation of Ministry of Health in Turkey. The MDA values for these samples were calculated as $0.011 \mathrm{~Bq}$ $\mathrm{L}^{-1}$ for gross alpha and $0.058 \mathrm{~Bq} \mathrm{~L}^{-1}$ for gross beta.

\section{Conclusions}

In emergency situations many samples have to be analyzed quickly and with sufficient sensitivities. All artificial radionuclides should be detected by LSS. Detection limits should be lower than reference levels fixed for countermeasures adoption. Therefore, in this case, LSS is employed as a screening technique in order to identify samples containing more radioactivity than expected (on the basis of natural radionuclides concentration). In this study, liquid scintillation spectrometric method was successfully used to determine the gross alpha/beta activity concentrations simultaneously in drinking water as an alternative screening procedure. The procedure was tested with spiked real water sample and actual comparison sample. The obtained results indicate that the method is effective and provides good accuracy and precision. Therefore, LSS can be employed as a screening technique in order to identify samples containing more radioactivity than the expected.

In addition, the results show that gross alpha/beta activity concentrations in drinking water in Turkey are allowable values and analyzed waters are safe for consumption from radioactivity point of view.

\section{References}

1. WHO, World Health Organization (3rd Ed.: incorporating 1st and 2nd addenda.): Vol.1: Recommendations: Guidelines for drinking-water quality, Geneva, 2008.

2. EU Council Directive (2013/51/Euroatom of 22 October 2013): Directive: laying down requirements for the protection of the health of the general public with regard to radioactive substances in water intended for human consumption, Official journal of the European Union, 2013.

3. Turkish Ministry of Health. Regulation About Natural Mineral Waters. Official Gazette No: 25657, 2004.

4. T. M. Semkow, P. P. Health Phys. 2001, 5, 567-574. http://dx.doi.org/10.1097/00004032-200111000-00011

5. C. F. Lin, J. J. Wang, J. C. Huang, C. H. Yeh, M. C. Yuan, B. J. Chang, Appl. Radiat. Isot. 2012, 70, 1981-1984. http://dx.doi.org/10.1016/j.apradiso.2012.02.041

6. N. Todorovic, J. Nikolov, B. Tenjovic, I. Bikit, M. Veskovic, Radiat. Meas. 2012, 47, 1053-1059. http://dx.doi.org/10.1016/j.radmeas.2012.09.009

7. L. Salonen, Radiochemistry 2006, 48, 606 -612. http://dx.doi.org/10.1134/S1066362206060142

8. J. I. Davilla Rangel, H. Lopez del Rio, B. L. Rodriguez, B. M. Solache-Rios, J. Radioanal. Nucl. Chem. 2001, 247, 425-428. http://dx.doi.org/10.1023/A:1006790626253

9. R. I. Kleinschmidt, Appl. Radiat. Isot. 2004, 61, 333-338. http://dx.doi.org/10.1016/j.apradiso.2004.03.004

10. S. R. Ruberu, Y. G. Liu, S. K. Perera, Health Phys. 2008, 95 , 397-406. http://dx.doi.org/10.1097/01.HP.0000318890.23635.f4

11. D. Zapata-Garcý'a, M. Llaurado', Study of instrumental parameters affecting the simultaneous measurement of gross alpha and gross beta activities in water samples: International Conference on Advances in Liquid Scintillation Spectrometry, Davos, Switzerland, 2008, Nebraska, USA, 2009, pp. 59-69.

12. M. J. Kessler, Liquid scintillation analysis, Science and Technology, Packard Instrument Company, USA, Pub. No: 169-3052, 1989.

13. C. Gilligan, A. Harms, NPL Report IR 27: Environmental Radioactivity Proficiency Test Exercise 2011, Acoustics and Ionizing Radiation Division, National Physical Laboratory, Teddington, UK, 2012, pp.10.

14. L. Currie, Anal. Chem. 1968, 40, 586-593. http://dx.doi.org/10.1021/ac60259a007

15. G. T. Cook, C. J. Passo, B. Carter, in: M. F. L. Annunziata (2nd Ed.): Environmental Liquid Scintillation Analysis, Handbook of Radioactivity Analysis, Academic Press, San Diego, USA, 1998, pp. 554.

16. R. Rusconi, A. Azzellino, S. Bellinzona, M. Forte, R. Gallini, G. Sgorbati, Anal. Bioanal. Chem. 2004, 379, 247-253. 


\section{Povzetek}

Določitev skupne koncentracije aktivnosti alfa in beta v pitni vodi je prvi korak okoljskih študij za spremljanje radioaktivnosti. Predstavlja hitro oceno radioaktivne obremenjenosti vzorca. V tej študiji smo določili proceduro s tekočinsko scintilacijsko spektrometrijo (LSS) za hkratno spremljanje skupne koncentracije aktivnosti alfa in beta v pitni vodi, potrdili njeno učinkovitost s testnim vzorcem in jo uporabili na dejanskih vzorcih pitne vode iz Turčije. Rezultati kažejo, da daje metoda dobro točnost in natančnost. LSS lahko uporabimo kot presejalno tehniko pri visokih koncentracijah aktivnosti. 